\title{
An Efficient One-Pot Green Protocol for the Synthesis of 5-Unsubstituted 3,4-Dihydropyrimidin-2(1H)-Ones Using Recyclable Amberlyst 15 DRY as a Heterogeneous Catalyst via Three-Component Biginelli-Like Reaction
}

\author{
Srinivasa Rao Jetti, Divya Verma, and Shubha Jain \\ Laboratory of Heterocycles, School of Studies in Chemistry \& Biochemistry, Vikram University, Ujjain 456010, Madhya Pradesh, India \\ Correspondence should be addressed to Srinivasa Rao Jetti, srinujetti479@gmail.com \\ Received 2 September 2012; Accepted 24 September 2012 \\ Academic Editors: J. M. Campagne and A. Hajra \\ Copyright (C) 2012 Srinivasa Rao Jetti et al. This is an open access article distributed under the Creative Commons Attribution \\ License, which permits unrestricted use, distribution, and reproduction in any medium, provided the original work is properly \\ cited. \\ An environmentally benign green protocol for the synthesis of 5-unsubstituted 3,4-dihydropyrimidin-2( $1 H$ )-ones using Amberlyst \\ $15 \mathrm{DRY}$ as a recyclable catalyst has been developed. The use of resinous, nontoxic, thermally stable, and inexpensive Amberlyst 15 \\ DRY, as a recyclable heterogeneous catalyst, makes the process simple with negligible chemical waste. Among the various solid acid \\ catalysts Amberlyst 15 DRY was found to be the most efficient catalyst with regard to reaction time, yield, and ease of work-up \\ procedure.
}

\section{Introduction}

Replacement of conventional, toxic, and polluting Bronsted and Lewis acid catalysts with ecofriendly reusable solid acid heterogeneous catalysts like acidic zeolites, clays, sulfated zirconia, and ion exchange resins is an area of current interest $[1,2]$. The use of solid acid catalyst instead of liquids includes many advantages, such as reduced equipment corrosion, ease of product separation, recycling of the catalyst, and environmental acceptability. In the recent past ion exchange resins in general and styrene-DVB matrix resin sulfonic acid (Amberlyst 15 DRY) in particular, which are strongly acidic and chemically as well as thermally stable, have been found to be excellent catalysts for a variety of the major organic reactions like esterification, alkylation, acylation, and condensation [3-8].

Pyrimidinones or dihydropyrimidinones (DHPMs) are well known for their wide range of bioactivities. Their applications in the field of drug research have stimulated the development of a wide range of synthetic methods for their preparation and chemical transformations. Out of the five major bases in nucleic acids three are pyrimidine derivatives which comprise of cytosine (1) which is found in DNA and RNA, uracil (2) in RNA and thymine, and (3) in DNA. Because of their involvement as bases in DNA and RNA, they have become very important in the world of synthetic organic chemistry. Aryl-substituted 3,4-dihydropyrimidin$2(1 H)$-one and their derivatives are an important class of substances in organic and medicinal chemistry (see Figure 1).

4-Aryl-1,4-dihydropyridines (DHPMs) of the Nifedipine type (4) [9] were first introduced into clinical medicine in 1975 and are still the most potent group of calcium channel modulators available for the treatment of cardiovascular diseases [10]. Dihydropyrimidines of type (5) show a very similar pharmacological profile, and in recent years, several related compounds were developed (5) that are equal in potency and duration of antihypertensive activity to classical and second-generation dihydropyridinedrugs [11]. (see Figure 2).

In an attempt to prepare DHPMs, different types of acidic catalysts such as $\mathrm{H}_{2} \mathrm{SO}_{4}$ [12], $\mathrm{BF}_{3} \cdot \mathrm{EtOH} / \mathrm{CuCl}$ [13], $\mathrm{LaCl}_{3} \cdot 7 \mathrm{H}_{2} \mathrm{O}$ with catalytic concentrated $\mathrm{HCl}$ [14], $\mathrm{CeCl}_{3} \cdot 7 \mathrm{H}_{2} \mathrm{O}$ [15], $\mathrm{InCl}_{3}$ [16], heteropolyacids [17], $\mathrm{BiCl}_{3}$ [18], $\mathrm{Cu}(\mathrm{OTf})_{2}$ [19], TMSCl [20], $\mathrm{LiClO}_{4}$ [21], LiBr [22], 
<smiles>Nc1ccnc(=O)[nH]1</smiles><smiles>O=c1cc[nH]c(=O)[nH]1</smiles><smiles>Cc1c[nH]c(=O)[nH]c1=O</smiles>

FIgURe 1

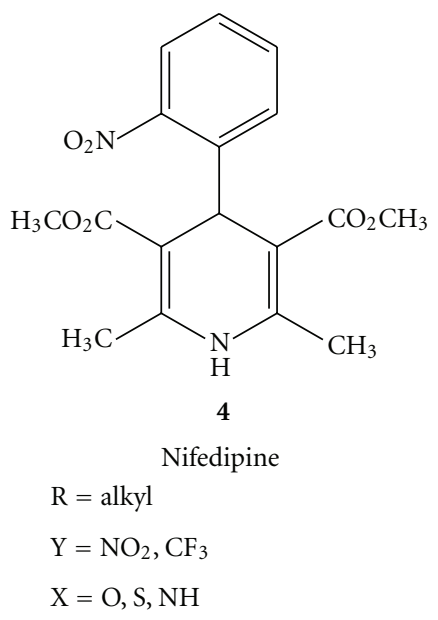<smiles>[R]C(=O)C1=C([X])NC(C)=C(C([R])=O)N1C([X])=O</smiles>

Figure 2

$\mathrm{InBr}_{3}$ [23], phenyl pyruvic acid [24], $\mathrm{FeCl}_{3} \cdot 6 \mathrm{H}_{2} \mathrm{O} / \mathrm{HCl}$ [25], TMSI [26], $\mathrm{CdCl}_{2}$ [27], $\mathrm{CuCl}_{2} \cdot 2 \mathrm{H}_{2} \mathrm{O}-\mathrm{HCl}$ [28], and $\mathrm{ZnBr}_{2}$ [29] have been used. However, inspite of their potential utility many of the existing methods suffer from the drawbacks, such as the use of strong acidic conditions, longer reaction times, tedious workup, environmental disposal problems, and lower yields of the products, leaving scope for further development of an efficient and versatile method for Biginelli reaction.

Growing concern about environmental damage leads to an urgent requirement for the development of ecofriendly technology and economic processes. It is of great practical importance to synthesize DHPM derivatives by the Biginelli reaction by using a solid acid catalyst, because of the ability to modify the acid strength, ease of handling, recycling of the catalyst, and environmental compatibility. In view of the above requirement, and as a part of our program towards green synthesis, we herein report a single-step and ecofriendly protocol for the synthesis of DHPM derivatives by the multicomponent reactions of 1,3-dicarbonyl compound, aldehydes, and urea (Scheme 1) over Amberlyst 15 DRY with good yields and selectivity.

\section{Results and Discussion}

To evaluate the catalytic effect of various ion exchange resins we started with the model reaction of ethylacetoacetate $(1.0 \mathrm{mmol})$ with benzaldehyde $(1.0 \mathrm{mmol})$ and urea $(1.2 \mathrm{mmol})$ in refluxing ethanol without and with use
TABLe 1: Catalytic activity of different ion exchange resins in Biginelli condensation ${ }^{\mathrm{a}}$.

\begin{tabular}{lccc}
\hline Entry & Ion exchange resin & Reaction time (h) & Yield (\%) \\
\hline 1 & - & 10 & Trace \\
2 & Amberlyst-70 & 3 & 81 \\
3 & Amberlyst 15 DRY a & 5.5 & 94 \\
4 & Indion-130 & 3 & 92.5 \\
5 & Indion-190 & 3.5 & 92 \\
6 & Nafion-H & 4.5 & 85 \\
7 & Envirocat EPZ10 & 6 & 84 \\
8 & Montmorillonite KSF & 10 & 38 \\
\hline
\end{tabular}

${ }^{a}$ Reaction conditions: ethyl acetoacetate $(1.0 \mathrm{mmol})$, benzaldehyde $(1.0 \mathrm{mmol})$, and urea $(1.2 \mathrm{mmol})$ in dry ethanol $(10 \mathrm{~mL})$, ion exchange resin $(50 \mathrm{mg})$ at refluxing temperature.

of Amberlyst-70 and Amberlyst 15 DRY as catalysts to afford dihydropyrimidine $\mathbf{1 a}$ and the results obtained were compared with those already reported using other catalysts $[30,31]$ (Table 1). It can be seen from Table 1 that Amberlyst 15 DRY is the most efficient among the five solid acidic ion exchange resins. It was found that $50 \mathrm{mg}$ of Amberlyst 15 DRY is sufficient to carry out the Biginelli reaction successfully. An increase in the amount of Amberlyst 15 DRY to more than $50 \mathrm{mg}$ showed no substantial improvement in the yield, whereas the yield is reduced by decreasing the amount of Amberlyst 15 DRY.

The effect of solvent on the reaction was studied (Table 2, entries 1-6) and ethanol was found to be the best solvent when considering the reaction yields and environmental damage.

The method can be used for wide range of reactants with different functional group. We have synthesized some novel compounds containing quinoline, pyrimidine, indole, and coumarin units (Table 3 ). All reactions proceeded expeditiously and delivered good yields with broad range of structurally diverse aromatic and heterocyclic aldehydes used in this condensation. $\alpha, \beta$-Unsaturated aldehydes react selectively with aldehyde functional group, whereas acid sensitive heterocyclic aldehydes exclusively gave dihydropyrimidinones in high yield. We found that electron donating or withdrawing group on aromatic aldehydes gave almost good to excellent yield. In all the cases the pure product was isolated by simple filtration without use of any chromatography or cumbersome reaction workup.

The resin catalyst was separated from the reaction mixture by filtration and can be reused several times without 
<smiles></smiles>
$\mathrm{X}=\mathrm{O}, \mathrm{S}$

SCHeme 1<smiles>[R]OC(=O)C1=C(C)NC([X])NC1[M]</smiles><smiles>[R]C([R16])O[Na]</smiles>

SCHEMe 2

TABLE 2: Optimization of the reaction conditions for the synthesis of $1 \mathrm{a}^{\mathrm{a}}$.

\begin{tabular}{lcccc}
\hline Entry & Catalyst & Solvent & Time (h) & Yield (\%) \\
\hline 1 & Amberlyst 15 DRY & Water & 4 & 90 \\
2 & Amberlyst 15 DRY & EtOH & 5.5 & 94 \\
3 & Amberlyst 15 DRY & $\mathrm{CH}_{3} \mathrm{CN}$ & 6.5 & 85 \\
4 & Amberlyst 15 DRY & THF & 6 & 87 \\
5 & Amberlyst 15 DRY & Benzene & 10 & Trace \\
6 & Amberlyst 15 DRY & Toluene & 10 & Trace \\
\hline
\end{tabular}

${ }^{a}$ All reactions were conducted at reflux temperature of the solvent used.

any appreciable loss in activity, which clearly proves the recyclability and reusability of the catalyst (Figure 3). It is noteworthy to mention that these reactions are working well without using any phase transfer catalyst. Furthermore, the protocol has its advantages lying in the ease of separation of catalyst and the product, which can be achieved by simple filtration.

The formation of product 2 (Scheme 2) probably involves the activation of the carbonyl function by Amberlyst 15 DRY, thereby making the methyl group readily enolisable, which in turn reacts with aldehyde and urea-derived imine in a Michael-type step to produce 2 (Table 4).

This investigation has been extended to cyclic ketones like cyclohexanone (Scheme 3 ). The products formed (3a-d) are listed in Table 5.

\section{Experimental}

3.1. General. All solvents and reagents were purchased from Aldrich and Merck with high-grade quality and used without any purification. The Indion-130 and Indion-190 were purchased from Ion Exchange India Ltd. Nafion-H,
TABLe 3: Amberlyst 15 DRY catalyzed synthesis of dihydropyrimidine-2-(1H)-ones/thiones.

\begin{tabular}{lcccccc}
\hline Entry & $\mathrm{R}^{1}$ & $\mathrm{R}^{2}$ & $\mathrm{X}$ & Products $^{\mathrm{a}}$ & Yield $^{\mathrm{b}}(\%)$ & $\mathrm{M} . \mathrm{P}\left({ }^{\circ} \mathrm{C}\right)$ \\
\hline 1 & $\mathrm{C}_{6} \mathrm{H}_{5}$ & $\mathrm{Et}$ & $\mathrm{O}$ & $\mathbf{1 a}$ & 89 & $205-207$ \\
2 & $4-\left(\mathrm{CH}_{3} \mathrm{O}\right)-\mathrm{C}_{6} \mathrm{H}_{4}$ & $\mathrm{Et}$ & $\mathrm{O}$ & $\mathbf{1 b}$ & 90 & $202-203$ \\
3 & $4-\left(\mathrm{NMe}_{2}\right)-\mathrm{C}_{6} \mathrm{H}_{4}$ & $\mathrm{Et}$ & $\mathrm{O}$ & $\mathbf{1 c}$ & 83 & $254-256$ \\
4 & $4-\mathrm{NO}_{2}-\mathrm{C}_{6} \mathrm{H}_{4}$ & $\mathrm{Et}$ & $\mathrm{O}$ & $\mathbf{1 d}$ & 94 & $212-213$ \\
5 & $4-(\mathrm{Cl})-\mathrm{C}_{6} \mathrm{H}_{4}$ & $\mathrm{Et}$ & $\mathrm{O}$ & $\mathbf{1 e}$ & 91 & $214-215$ \\
6 & $4-\left(\mathrm{NO}_{2}\right) \mathrm{C}_{6} \mathrm{H}_{4}$ & $\mathrm{Me}$ & $\mathrm{O}$ & $\mathbf{1 f}$ & 95 & $237-239$ \\
7 & $4-\left(\mathrm{CH}_{3} \mathrm{O}\right)-\mathrm{C}_{6} \mathrm{H}_{4}$ & $\mathrm{Me}$ & $\mathrm{O}$ & $\mathbf{1 g}$ & 84 & $192-193$ \\
8 & $\mathrm{C}_{6} \mathrm{H}_{5}-\mathrm{CH}=\mathrm{CH}$ & $\mathrm{Et}$ & $\mathrm{O}$ & $\mathbf{1 h}$ & 94 & $231-233$ \\
9 & $3-\mathrm{NO}_{2}-\mathrm{C}_{6} \mathrm{H}_{4}$ & Et & $\mathrm{S}$ & $\mathbf{1 i}$ & 92 & $206-207$ \\
10 & $4-\left(\mathrm{CH}_{3} \mathrm{O}\right)-\mathrm{C}_{6} \mathrm{H}_{4}$ & Et & $\mathrm{S}$ & $\mathbf{1 j}$ & 90 & $154-156$ \\
11 & $\mathrm{C}_{4} \mathrm{H}_{4} \mathrm{~N}$ & $\mathrm{Et}$ & $\mathrm{O}$ & $\mathbf{1 k}$ & 83 & $180-182$ \\
12 & $\mathrm{C}_{4} \mathrm{H}_{3} \mathrm{O}$ & Et & $\mathrm{O}$ & $\mathbf{1 l}$ & 85 & $211-213$ \\
13 & $\mathrm{C}_{4} \mathrm{H}_{3} \mathrm{~S}$ & Et & $\mathrm{O}$ & $\mathbf{1 m}$ & 86 & $201-203$ \\
14 & $\mathrm{C}_{8} \mathrm{H}_{6} \mathrm{~N}$ & Et & $\mathrm{O}$ & $\mathbf{1 n}$ & 80 & $212-214$ \\
15 & $\mathrm{C}_{5} \mathrm{H}_{4} \mathrm{~N}$ & Et & $\mathrm{O}$ & $\mathbf{1 0}$ & 91 & $193-194$ \\
16 & $\mathrm{C}_{5} \mathrm{H}_{4} \mathrm{~N}$ & Et & $\mathrm{S}$ & $\mathbf{1 p}$ & 85 & $168-169$ \\
17 & $\mathrm{C}_{9} \mathrm{H}_{6} \mathrm{~N}$ & Et & $\mathrm{O}$ & $\mathbf{1 q}$ & 91 & $245-247$ \\
18 & $\mathrm{C}_{4} \mathrm{H}_{3} \mathrm{~N}_{2}$ & Et & $\mathrm{O}$ & $\mathbf{1 r}$ & 89 & $255-257$ \\
19 & $\mathrm{C}_{10} \mathrm{H}_{7}$ & Et & $\mathrm{O}$ & $\mathbf{1 s}$ & 92 & $182-185$ \\
20 & $\mathrm{C}_{9} \mathrm{H}_{5} \mathrm{O}_{3}$ & Et & $\mathrm{O}$ & $\mathbf{1 t}$ & 89 & $277-279$ \\
\hline
\end{tabular}

Reaction conditions: $\beta$-ketoester $(1.0 \mathrm{mmol})$, aldehyde $(1.0 \mathrm{mmol})$, and urea/thiourea $(1.2 \mathrm{mmol})$ in dry ethanol $(10 \mathrm{~mL})$, ion exchange resin $(50 \mathrm{mg})$ at refluxing temperature. ${ }^{\mathrm{b}}$ Isolated yields.

Amberlyst-70, and Amberlyst 15 DRY were purchased from Aldrich. Melting points were determined on electrothermal apparatus by using open capillaries and are uncorrected. Thin-layer chromatography was accomplished on $0.2-\mathrm{mm}$ precoated plates of silica gel G60 F254 (Merck). Visualization 


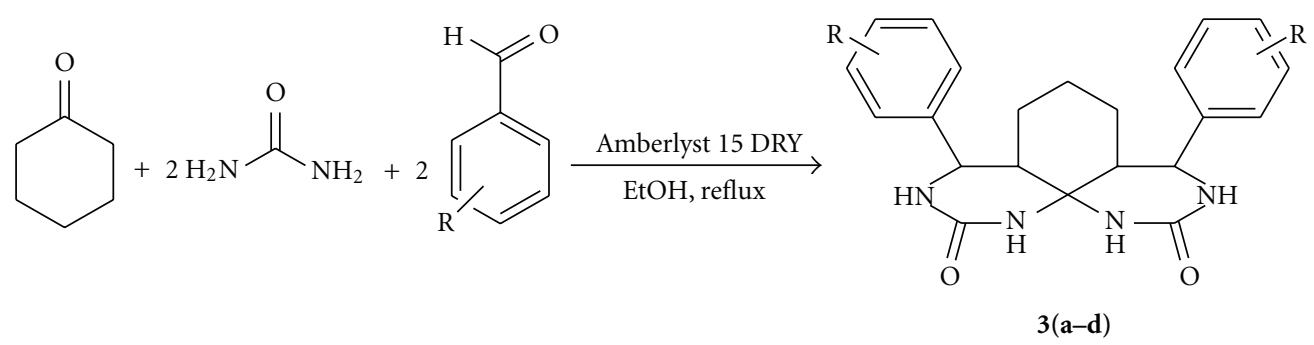

SCHeme 3

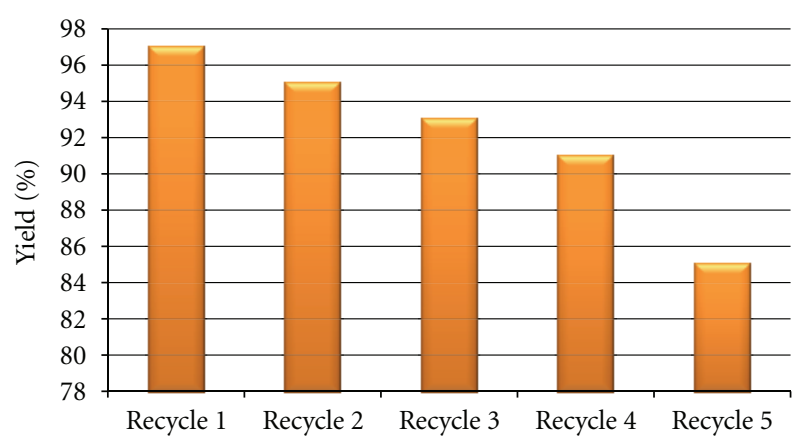

FIGURE 3: Graphical representation of recycle data for the reaction of EAA, benzaldehyde, and urea using Amberlyst 15 DRY.

was made with UV light (254 and $365 \mathrm{~nm}$ ) or with an iodine vapor. IR spectra were recorded on a FTIR-8400 spectrophotometer using DRS prob. ${ }^{1} \mathrm{H}-\mathrm{NMR}$ and ${ }^{13} \mathrm{C}-\mathrm{NMR}$ spectra were recorded in DMSO- $d_{6}$ solutions on a Bruker AVANCE 400NMR spectrometer operating at $400\left({ }^{1} \mathrm{H}\right)$ and $100\left({ }^{13} \mathrm{C}\right) \mathrm{MHz}$. LCMS analysis (EI, 70 V) was performed on a Hewlett-Packard HP 5971 instrument. All compounds were characterized by comparison of physical and spectral data with reported data [32-35] (see Figure 4, Table 6).

3.2. General Procedure for the Synthesis of 4-Aryl Substituted 3,4-Dihydropyrimidin-2-(1H)-ones/thiones. A mixture of $\beta$ diketone $(1.0 \mathrm{mmol})$, aldehyde $(1.0 \mathrm{mmol})$, urea/thiourea $(1.2 \mathrm{mmol})$, and Amberlyst $15 \mathrm{DRY}(50 \mathrm{mg})$ in anhydrous ethanol $(10 \mathrm{~mL})$ was refluxed for an appropriate time as indicated by TLC. After completion of the reaction the catalyst was filtered and washed with ethyl acetate until free from organic material. The solvent was evaporated at reduced pressure and obtained solid was crystallized from ethanol to afford pure 3,4-dihydropyrimidin-2-(1H)ones/thiones $\mathbf{1}(\mathbf{a}-\mathbf{t})$ in excellent yields.

3.3. General Procedure for the Synthesis of 3,4-Dihydro-4,6diphenylpyrimidin-2(1H)-ones. A mixture of acetophenone $(1.0 \mathrm{mmol})$, aldehyde $(1.0 \mathrm{mmol})$, urea $(1.5 \mathrm{mmol})$ and Amberlyst 15 DRY $(50 \mathrm{mg})$ in anhydrous ethanol $(10 \mathrm{~mL})$ was refluxed for an appropriate time as indicated by TLC. After completion of the reaction the catalyst was filtered and washed with ethyl acetate until free from organic material. The solvent was evaporated at reduced pressure and the solid obtained was recrystallised from ethanol to afford pure
TABLE 4: Amberlyst 15 DRY catalyzed synthesis of 5-unsubstitued 3,4-dihydropyrimidin-2(1H)-ones $2(\mathbf{a}-\mathbf{f})$.

\begin{tabular}{lcccc}
\hline Entry & $\mathrm{R}$ & Products $^{\mathrm{a}}$ & Yield $^{\mathrm{b}}(\%)$ & M.P $\left({ }^{\circ} \mathrm{C}\right)$ \\
\hline 1 & $\mathrm{C}_{6} \mathrm{H}_{5}$ & 2a & 90 & $233-236$ \\
2 & $4-(\mathrm{Cl})-\mathrm{C}_{6} \mathrm{H}_{4}$ & 2b & 92 & $267-269$ \\
3 & $4-\left(\mathrm{CH}_{3}\right)-\mathrm{C}_{6} \mathrm{H}_{4}$ & 2c & 86 & $248-250$ \\
4 & $4-\left(\mathrm{CH}_{3} \mathrm{O}\right)-\mathrm{C}_{6} \mathrm{H}_{4}$ & 2d & 84 & $259-261$ \\
5 & $2-(\mathrm{Cl})-\mathrm{C}_{6} \mathrm{H}_{4}$ & 2e & 91 & $260-263$ \\
6 & $3-\left(\mathrm{CH}_{3} \mathrm{O}\right)-\mathrm{C}_{6} \mathrm{H}_{4}$ & 2f & 88 & $256-258$ \\
\hline
\end{tabular}

${ }^{a}$ Reaction conditions: acetophenone $(1.0 \mathrm{mmol})$, benzaldehyde $(1.0 \mathrm{mmol})$, and urea $(1.5 \mathrm{mmol})$ in dry ethanol $(10 \mathrm{~mL})$, ion exchange resin $(50 \mathrm{mg})$ at refluxing temperature. ${ }^{\mathrm{b}}$ Isolated yields.

TABLE 5: Amberlyst 15 DRY catalyzed reaction of cyclohexanone, aldehyde, and urea.

\begin{tabular}{lcccc}
\hline Entry & $\mathrm{R}$ & Products $^{\mathrm{a}}$ & Yield $^{\mathrm{b}}(\%)$ & M.P $\left({ }^{\circ} \mathrm{C}\right)$ \\
\hline 1 & $\mathrm{C}_{6} \mathrm{H}_{5}$ & 3a & 93 & $327-329$ \\
2 & $4-\left(\mathrm{NO}_{2}\right) \mathrm{C}_{6} \mathrm{H}_{4}$ & 3b & 85 & $341-343$ \\
3 & $4-\left(\mathrm{CH}_{3}\right) \mathrm{C}_{6} \mathrm{H}_{4}$ & 3c & 89 & $348-351$ \\
4 & $2-(\mathrm{Cl})-\mathrm{C}_{6} \mathrm{H}_{4}$ & 3d & 88 & $321-323$ \\
\hline
\end{tabular}

${ }^{a}$ Reaction conditions: cyclohexanone $(1.0 \mathrm{mmol})$, aldehyde $(2.0 \mathrm{mmol})$, and urea $(3.0 \mathrm{mmol})$ in dry ethanol $(10 \mathrm{~mL})$, ion exchange resin $(50 \mathrm{mg})$ at refluxing temperature. ${ }^{\mathrm{b}}$ Isolated yields.

3,4-dihydro-4,6-diphenylpyrimidine-2(1H)-ones $\mathbf{2}(\mathbf{a}-\mathbf{f})$ in excellent yields.

3.4. General Procedure for the Reaction of Cyclohexanone, Aldehydes, and Urea. A mixture of cyclohexanone $(1.0 \mathrm{mmol})$, aldehyde $(2.0 \mathrm{mmol})$, urea $(3.0 \mathrm{mmol})$ and Amberlyst 15 DRY $(50 \mathrm{mg})$ in anhydrous ethanol $(10 \mathrm{~mL})$ was refluxed for an appropriate time as indicated by TLC. After completion of the reaction the catalyst was filtered and washed with ethyl acetate until free from organic material. The solvent was evaporated at reduced pressure and the solid obtained was recrystallised from ethanol to afford the desired spirofused heterotricyclic products $\mathbf{3}(\mathbf{a}-\mathbf{d})$ in $85-92 \%$ yield.

\subsection{Spectral Data of Compounds}

5-(Ethoxycarbonyl)-6-methyl-4-phenyl-3,4-dihydropyrimidin -2(1H)-one (1a). Mp 205-207 ${ }^{\circ}$; ${ }^{1} \mathrm{HNMR}$ (DMSO- $d_{6}$ ) $\delta$ : $1.09\left(\mathrm{t}, 3 \mathrm{H}, J=7.1 \mathrm{~Hz}, \mathrm{OCH}_{2} \mathrm{CH}_{3}\right), 2.25\left(\mathrm{~s}, 3 \mathrm{H}, \mathrm{CH}_{3}\right)$, $3.97(\mathrm{q}, 2 \mathrm{H}, J=7.1 \mathrm{~Hz}, \mathrm{OCH} 2), 5.05(\mathrm{~d}, 1 \mathrm{H}, J=2.15$ 
TABLE 6: Physical properties of Amberlyst 15 DRY.

\begin{tabular}{|c|c|}
\hline Physical form & Opaque beads \\
\hline Ionic form as shipped & Hydrogen \\
\hline Concentration of acid sites & $\geq 4.7 \mathrm{eq} / \mathrm{Kg}$ \\
\hline Water content & $\leq 1.5 \%\left(\mathrm{H}^{+}\right.$form $)$ \\
\hline Shipped weight & $610 \mathrm{~g} / \mathrm{L}(38 \mathrm{lbs} / \mathrm{ft})$ \\
\hline Fines content & $<0.300 \mathrm{~mm}: 1.0 \% \max$ \\
\hline Surface area & $45 \mathrm{~m}^{2} / \mathrm{g}$ \\
\hline Average pore diameter & $250 \AA$ \\
\hline \multicolumn{2}{|l|}{ Swelling } \\
\hline \multicolumn{2}{|l|}{60 to $70 \%$ (dry to Water) } \\
\hline \multicolumn{2}{|l|}{10 to $15 \%$ (dry to hexane) } \\
\hline \multicolumn{2}{|l|}{10 to $15 \%$ (dry to toluene) } \\
\hline \multicolumn{2}{|l|}{15 to $20 \%$ (dry to ethylene dichloride) } \\
\hline \multicolumn{2}{|l|}{30 to $40 \%$ (dry to ethyl acetate) } \\
\hline \multicolumn{2}{|l|}{60 to $70 \%$ (dry to ethyl alcohol, $95 \%$ ) } \\
\hline \multicolumn{2}{|l|}{15 to $20 \%$ (dry to phenol) } \\
\hline 3 to $5 \%$ (dry to benzene) & \\
\hline
\end{tabular}

Structure of Amberlyst 15 DRY

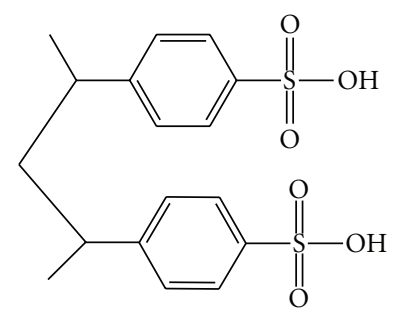

Polymer supported sulphonic acid

FIGURE 4
5-(Ethoxycarbonyl)-4-(4-dimethylamino-phenyl)-6-methyl3,4-dihydropyrimidin-2(1H)-one (1c). Mp $254-256{ }^{\circ} \mathrm{C} ;{ }^{1} \mathrm{H}$ $\mathrm{NMR}\left(\mathrm{DMSO}-d_{6}\right) \delta: 0.99\left(\mathrm{t}, 3 \mathrm{H}, J=7.12 \mathrm{~Hz}, \mathrm{OCH}_{2} \mathrm{CH}_{3}\right)$, $2.11\left(\mathrm{~s}, 3 \mathrm{H}, \mathrm{CH}_{3}\right), 2.84\left(\mathrm{~s}, 6 \mathrm{H}, \mathrm{N}\left(\mathrm{CH}_{3}\right)_{2}\right), 4.09(\mathrm{q}, 2 \mathrm{H}$, $\left.J=7.12 \mathrm{~Hz}, \mathrm{OCH}_{2} \mathrm{CH}_{3}\right), 5.05(\mathrm{~d}, 1 \mathrm{H}, J=2.21,-\mathrm{CH}), 6.42$ $(\mathrm{d}, 2 \mathrm{H}, J=8.55, \mathrm{Ar}-\mathrm{H}), 7.12(\mathrm{~d}, 2 \mathrm{H}, J=8.56, \mathrm{Ar}-\mathrm{H}), 7.15$ (s, $1 \mathrm{H}, \mathrm{NH}), 9.05$ (s, $1 \mathrm{H}, \mathrm{NH}) ;{ }^{13} \mathrm{C}-\mathrm{NMR}$ (DMSO-d $) \delta: 14.28$, $18.78,44.47,55.23,60.15,101.60,112.05,125.65,134.25$, 141.16, 153.46, 159.02, 165.24; IR ( $\nu_{\max }$; $\left.\mathrm{KBr}, \mathrm{cm}^{-1}\right): 3242$, 1721, 1637; ESI-MS $304(\mathrm{M}+\mathrm{H}) ; \mathrm{C}_{16} \mathrm{H}_{21} \mathrm{~N}_{3} \mathrm{O}_{3}$; (303.36); Calcd. C, 63.35; H, 6.98; N, 13.85; O, 15.82. Found. C, 63.38; H, 6.93; N, 13.87; O, 15.79.

5-(Ethoxycarbonyl)-4-(4-nitrophenyl)-6-methyl-3,4-dihydropyrimidin-2(1H)-one (1d). Mp 212-213 ${ }^{\circ} \mathrm{C} ;{ }^{1} \mathrm{H}-\mathrm{NMR}$ $\left(\mathrm{DMSO}-d_{6}\right) \delta: 1.11\left(\mathrm{t}, 3 \mathrm{H}, J=7.04 \mathrm{~Hz}, \mathrm{OCH}_{2} \mathrm{CH}_{3}\right), 2.32$ $\left(\mathrm{s}, 3 \mathrm{H}, \mathrm{CH}_{3}\right), 4.03\left(\mathrm{q}, 2 \mathrm{H}, J=7.12 \mathrm{~Hz}, \mathrm{OCH}_{2} \mathrm{CH}_{3}\right), 5.78$ (d, $1 \mathrm{H}, J=2.28,-\mathrm{CH}), 7.51(\mathrm{~d}, 2 \mathrm{H}, J=9.18, \mathrm{Ar}-\mathrm{H}), 7.69(\mathrm{~s}$, $1 \mathrm{H}, \mathrm{NH}), 8.16$ (d, 2H, $J=9.16, \mathrm{Ar}-\mathrm{H}), 9.05$ (s, 1H, NH); ${ }^{13} \mathrm{C}-\mathrm{NMR}$ (DMSO- $\left.d_{6}\right) \delta: 14.22,18.71,55.81,60.15,101.60$, $118.15,130.37,138.34,152.26,153.41,159.15,165.85$; IR $\left(\nu_{\max } ; \mathrm{KBr}, \mathrm{cm}^{-1}\right): 3235,1740,1631$; ESI-MS $306(\mathrm{M}+\mathrm{H})$; $\mathrm{C}_{14} \mathrm{H}_{15} \mathrm{~N}_{3} \mathrm{O}_{5}$; (305.29); Calcd. C, 55.08; H, 4.95; N, 13.76; O, 26.20. Found. C, 55.10; H, 4.93; N, 13.79; O, 26.16.

5-(Ethoxycarbonyl)-4-(4-chlorophenyl)-6-methyl-3,4-dihydropyrimidin-2(1H)-one (1e). Mp 214-215 ${ }^{\circ} \mathrm{C} ;{ }^{1} \mathrm{H}-\mathrm{NMR}$ $\left(\mathrm{DMSO}-d_{6}\right) \delta: 1.12\left(\mathrm{t}, 3 \mathrm{H}, J=7.14 \mathrm{~Hz}, \mathrm{OCH}_{2} \mathrm{CH}_{3}\right), 2.30$ (s, 3H, $\left.\mathrm{CH}_{3}\right), 3.91$ (q, 2H, $\left.J=7.16 \mathrm{~Hz}, \mathrm{OCH}_{2} \mathrm{CH}_{3}\right), 5.70$ (d, $1 \mathrm{H}, J=2.28,-\mathrm{CH}), 7.21(\mathrm{~d}, 2 \mathrm{H}, J=9.18, \mathrm{Ar}-\mathrm{H}), 7.69(\mathrm{~s}$, $1 \mathrm{H}, \mathrm{NH}), 7.94(\mathrm{~d}, 2 \mathrm{H}, J=9.18, \mathrm{Ar}-\mathrm{H}), 9.16(\mathrm{~s}, 1 \mathrm{H}, \mathrm{NH})$; ${ }^{13} \mathrm{C}-\mathrm{NMR}\left(\mathrm{DMSO}-d_{6}\right) \delta: 14.18,18.62,55.72,60.21,101.55$, $118.17,130.32,142.29,152.31,153.39,159.17,165.83$; IR $\left(\nu_{\max } ; \mathrm{KBr}, \mathrm{cm}^{-1}\right): 3225,1720,1615$; ESI-MS $295(\mathrm{M}+\mathrm{H})$; $\mathrm{C}_{14} \mathrm{H}_{15} \mathrm{ClN}_{2} \mathrm{O}_{3}$; Calcd. C, 57.05; H, 5.13; Cl, 12.03; N, 9.50; O, 16.29. Found. C, 57.08; H, 5.10; Cl, 12.06; N, 9.47; O, 16.31 .

5-(Methoxycarbonyl)-4-(4-nitrophenyl)-6-methyl-3,4-dihydropyrimidin-2(1H)-one (1f). Mp 237-239 ${ }^{\circ}$; ${ }^{1} \mathrm{H}-\mathrm{NMR}$ $\left(\mathrm{DMSO}-d_{6}\right) \delta: 2.21\left(\mathrm{~s}, 3 \mathrm{H}, \mathrm{CH}_{3}\right), 3.90\left(\mathrm{~s}, 3 \mathrm{H},-\mathrm{COOCH}_{3}\right)$, $5.51(\mathrm{~d}, 1 \mathrm{H}, J=2.15,-\mathrm{CH}), 7.42(\mathrm{~d}, 2 \mathrm{H}, J=9.11, \mathrm{Ar}-\mathrm{H})$, 7.44 (s, 1H, NH), 8.05 (d, 2H, J = 9.10, Ar-H), 9.05 (s, 1H, $\mathrm{NH}) ;{ }^{13} \mathrm{C}-\mathrm{NMR}$ (DMSO- $\left.d_{6}\right) \delta: 18.64,52.40,55.40,109.60$, $113.23,128.31,137.20,149.65,155.45,160.36,166.20$; IR $\left(\nu_{\text {max }} ; \mathrm{KBr}, \mathrm{cm}^{-1}\right): 3232,1724,1631$; ESI-MS $292(\mathrm{M}+\mathrm{H})$; $\mathrm{C}_{13} \mathrm{H}_{13} \mathrm{~N}_{3} \mathrm{O}_{5}$; (291.26); Calcd. C, 53.61; H, 4.50; N, 14.43; O, 27.47. Found. C, 53.64; H, 4.47, N, 14.46; O, 27.44.

5-(Methoxycarbonyl)-4-(4-methoxyphenyl)-6-methyl-3,4-dihydropyrimidin-2(1H)-one (1g). Mp 192-193 ${ }^{\circ} \mathrm{C} ;{ }^{1} \mathrm{H}-\mathrm{NMR}$ $\left(\mathrm{DMSO}-d_{6}\right) \delta: 2.24\left(\mathrm{~s}, 3 \mathrm{H}, \mathrm{CH}_{3}\right), 3.92\left(\mathrm{~s}, 3 \mathrm{H},-\mathrm{COOCH}_{3}\right)$, $3.75\left(\mathrm{~s}, 3 \mathrm{H},-\mathrm{OCH}_{3}\right), 5.22(\mathrm{~d}, 1 \mathrm{H}, J=2.21-\mathrm{CH}), 6.76(\mathrm{~d}$, $2 \mathrm{H}, J=8.58, \mathrm{Ar}-\mathrm{H}), 7.18(\mathrm{~d}, 2 \mathrm{H}, J=8.58, \mathrm{Ar}-\mathrm{H}), 7.62(\mathrm{~s}$, $1 \mathrm{H}, \mathrm{NH}), 9.15$ (s, $1 \mathrm{H}, \mathrm{NH}) ;{ }^{13} \mathrm{C}-\mathrm{NMR}$ (DMSO-d $) \delta: 18.61$, 53.36, 55.05, 55.87, 108.54, 113.21, 128.47, 137.64, 148.54, 154.16, 160.81, 165.94; IR ( $\left.\nu_{\max } ; \mathrm{KBr}, \mathrm{cm}^{-1}\right)$ : 3242, 1721, 1637; ESI-MS $277(\mathrm{M}+\mathrm{H})$; $\mathrm{C}_{14} \mathrm{H}_{16} \mathrm{~N}_{2} \mathrm{O}_{4}$; (276.29); Calcd.
Cacld. C, 62.06; H, 6.25; N, 9.65; O, 22.04. Found. C, 62.08; H, 6.22; N, 9.69; O, 22.02.
5-(Ethoxycarbonyl)-4-(4-methoxyphenyl)-6-methyl-3,4-dihydropyrimidin-2(1H)-one (1b). Mp 202-203 ${ }^{\circ} \mathrm{C}$; ${ }^{1} \mathrm{H}-\mathrm{NMR}$ $\left.3 \mathrm{H}, \mathrm{CH}_{3}\right), 3.78\left(\mathrm{~s}, 3 \mathrm{H},-\mathrm{OCH}_{3}\right), 4.06(\mathrm{q}, 2 \mathrm{H}, J=7.12 \mathrm{~Hz}$ $\left.\mathrm{OCH}_{2} \mathrm{CH}_{3}\right), 5.34(\mathrm{~d}, 1 \mathrm{H}, J=2.28-\mathrm{CH}), 6.82(\mathrm{~d}, 2 \mathrm{H}$, $J=8.60, \mathrm{Ar}-\mathrm{H}), 7.22(\mathrm{~d}, 2 \mathrm{H}, J=8.60, \mathrm{Ar}-\mathrm{H}), 7.76(\mathrm{~s}, 1 \mathrm{H}$, $\mathrm{NH}), 9.26(\mathrm{~s}, 1 \mathrm{H}, \mathrm{NH}) ;{ }^{13} \mathrm{C}-\mathrm{NMR}$ (DMSO-d $\left.d_{6}\right) \delta: 14.32$, $18.80,55.23,55.40,60.17,101.68,114.06,127.97,136.22$, $146.16,153.59,159.30,165.87$; IR $\left(\nu_{\max } ; \mathrm{KBr}, \mathrm{cm}^{-1}\right): 3232$, 1720, 1638; ESI-MS $291(\mathrm{M}+\mathrm{H}) ; \mathrm{C}_{15} \mathrm{H}_{18} \mathrm{~N}_{2} \mathrm{O}_{4}(290.31)$

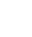


C, 60.86; H, 5.84; N, 10.14; O, 23.16. Found. C, 60.89; H, $5.81, \mathrm{~N}, 10.17 ; \mathrm{O}, 23.13$.

5-(Ethoxycarbonyl)-6-methyl-4-styryl-3,4-dihydropyrimidin2(1H)-one (1h). Mp 231-233 ${ }^{\circ} \mathrm{C} ;{ }^{1} \mathrm{H}-\mathrm{NMR}$ (DMSO-d 6 ) $\delta$ : $1.20\left(\mathrm{t}, 3 \mathrm{H}, \mathrm{J}=7.0 \mathrm{~Hz}, \mathrm{OCH}_{2} \mathrm{CH}_{3}\right), 2.21\left(\mathrm{~s}, 3 \mathrm{H}, \mathrm{CH}_{3}\right), 4.09$ $\left(\mathrm{q}, 2 \mathrm{H}, \mathrm{J}=7.05 \mathrm{~Hz}, \mathrm{OCH}_{2} \mathrm{CH}_{3}\right), 4.74(\mathrm{~d}, 1 \mathrm{H}, J=4.80$, $-\mathrm{CH}), 6.20(\mathrm{dd}, J=15.8,6.0 \mathrm{~Hz}, 1 \mathrm{H}, \mathrm{CH}=\mathrm{C}-\mathrm{H}), 6.37(\mathrm{~d}$, $J=15.9 \mathrm{~Hz}, 1 \mathrm{H}, \mathrm{H}-\mathrm{C}=\mathrm{CH}) 7.21-7.46(\mathrm{~m}, 5 \mathrm{H}, \mathrm{Ar}-\mathrm{H}), 7.53$ $(\mathrm{s}, 1 \mathrm{H}, \mathrm{NH}), 9.14(\mathrm{~s}, 1 \mathrm{H}, \mathrm{NH}) ;{ }^{13} \mathrm{C}-\mathrm{NMR}\left(\mathrm{DMSO}-d_{6}\right) \delta$ : $14.21,17.31,51.84,59.45,98.54,127.34,128.54,129.54$, $130.59,131.24,135.24,145.34,153.62,165.23$; IR ( $\nu_{\max }$; $\left.\mathrm{KBr}, \mathrm{cm}^{-1}\right)$ : 3242, 1704, 1652; ESI-MS $287(\mathrm{M}+\mathrm{H})$; $\mathrm{C}_{16} \mathrm{H}_{18} \mathrm{~N}_{2} \mathrm{O}_{3}$; (286.33); Calcd. C, 67.12; H, 6.34; N, 9.78; O, 16.76. Found. C, 67.15; H, 6.32; N, 9.81; O, 16.73.

5-(Ethoxycarbonyl)-4-(3-nitrophenyl)-6-methyl-3,4-dihydropyrimidin-2(1H)-thione (1i). Mp $206-207^{\circ} \mathrm{C} ;{ }^{1} \mathrm{H}-\mathrm{NMR}$ $\left(\mathrm{DMSO}-d_{6}\right) \delta: 1.15\left(\mathrm{t}, 3 \mathrm{H}, J=7.14 \mathrm{~Hz}, \mathrm{OCH}_{2} \mathrm{CH}_{3}\right), 2.27$ $\left(\mathrm{s}, 3 \mathrm{H}, \mathrm{CH}_{3}\right), 4.02\left(\mathrm{q}, 2 \mathrm{H}, J=7.11 \mathrm{~Hz}, \mathrm{OCH}_{2} \mathrm{CH}_{3}\right), 5.81$ $(\mathrm{d}, 1 \mathrm{H}, J=2.06,-\mathrm{CH}), 7.23-7.37(\mathrm{~m}, 4 \mathrm{H}, \mathrm{Ar}-\mathrm{H}), 7.78$ $(\mathrm{s}, 1 \mathrm{H}, \mathrm{NH}), 9.34(\mathrm{~s}, 1 \mathrm{H}, \mathrm{NH}) ;{ }^{13} \mathrm{C}-\mathrm{NMR}\left(\mathrm{DMSO}-d_{6}\right) \delta$ : $14.14,18.60,55.64,60.21,101.34,126.25,128.02,129.32$, $130.75,135.65,144.34,160.40,165.64,182.65$; IR $\left(\nu_{\max }\right.$; $\left.\mathrm{KBr}, \mathrm{cm}^{-1}\right): 3245,1725,1632,1575,1545$; ESI-MS $322(\mathrm{M}$ $+\mathrm{H}) ; \mathrm{C}_{14} \mathrm{H}_{15} \mathrm{~N}_{3} \mathrm{O}_{4} \mathrm{~S}$; (321.35); Calcd. C, 52.33; H, 4.70; N, 13.08; O, 19.92; S, 9.98. Found. C, 52.36; H, 4.66; N, 13.11; O, 19.88; S, 9.99 .

5-(Ethoxycarbonyl)-4-(4-methoxyphenyl)-6-methyl-3,4-dihydropyrimidin-2(1H)-thione (1j). Mp $154-156^{\circ} \mathrm{C} ;{ }^{1} \mathrm{H}-\mathrm{NMR}$ $\left(\mathrm{DMSO}-d_{6}\right) \delta: 1.17\left(\mathrm{t}, 3 \mathrm{H}, J=7.11 \mathrm{~Hz}, \mathrm{OCH}_{2} \mathrm{CH}_{3}\right), 2.37(\mathrm{~s}$, $\left.3 \mathrm{H}, \mathrm{CH}_{3}\right), 4.12\left(\mathrm{~s}, 3 \mathrm{H},-\mathrm{OCH}_{3}\right), 4.15(\mathrm{q}, 2 \mathrm{H}, J=7.10 \mathrm{~Hz}$, $\left.\mathrm{OCH}_{2} \mathrm{CH}_{3}\right), 5.44(\mathrm{~d}, 1 \mathrm{H}, J=2.15-\mathrm{CH}), 7.11(\mathrm{~d}, 2 \mathrm{H}$, $J=8.15, \mathrm{Ar}-\mathrm{H}), 7.37$ (d, $2 \mathrm{H}, J=8.11, \mathrm{Ar}-\mathrm{H}), 7.84(\mathrm{~s}, 1 \mathrm{H}$, $\mathrm{NH}), 9.43(\mathrm{~s}, 1 \mathrm{H}, \mathrm{NH}) ;{ }^{13} \mathrm{C}-\mathrm{NMR}\left(\mathrm{DMSO}-d_{6}\right) \delta: 14.32$, $18.05,55.24,55.49,60.45,101.84,114.32,127.74,137.25$, 147.15, 159.45, 165.62, 182.48; IR $\left(\nu_{\max } ; \mathrm{KBr}, \mathrm{cm}^{-1}\right): 3240$, 1725, 1635, 1574, 1540; ESI-MS $307(\mathrm{M}+\mathrm{H}) ; \mathrm{C}_{15} \mathrm{H}_{18} \mathrm{~N}_{2} \mathrm{O}_{3} \mathrm{~S}$; (306.38); Calcd. C, 58.80; H, 5.92; N, 9.14; O, 15.67; S, 10.47. Found. C, 58.84; H, 5.89; N, 9.17; O, 15. 64; S, 10.49 .

5-(Ethoxycarbonyl)-4-(3-1H-indole)-6-methyl-3,4-dihydropyrimidin-2(1H)-one (1n). Mp. $212-214^{\circ} \mathrm{C} ;{ }^{1} \mathrm{H}-\mathrm{NMR}$ $\left(\mathrm{DMSO}-d_{6}\right) \delta: 9.17(\mathrm{~s}, 1 \mathrm{H}, \mathrm{NH}), 7.04(\mathrm{~s}, 1 \mathrm{H}, \mathrm{NH}), 8.48$ (s, 1H, NH), $7.76(\mathrm{~s}, 1 \mathrm{H}), 7.18-7.34(\mathrm{~m}, 4 \mathrm{H}), 5.23(\mathrm{~d}, 1 \mathrm{H}$, $J=3.7 \mathrm{~Hz}), 3.97(\mathrm{q}, 2 \mathrm{H}, J=7.2 \mathrm{~Hz}), 2.24(\mathrm{~s}, 3 \mathrm{H}), 1.15(\mathrm{t}$, $3 \mathrm{H}, J=7.2 \mathrm{~Hz}) ;{ }^{13} \mathrm{C}-\mathrm{NMR}\left(\mathrm{DMSO}-d_{6}\right) \delta: 172.10,155.25$, $152.90,136.90,127.30,123.20,121.80,119.10,118.90$, $111.15,106.90,104.35,60.10,34.15,14.90,13.90$. IR ( $\nu_{\max }$; $\left.\mathrm{KBr}, \mathrm{cm}^{-1}\right)$ : 3417, 3356, 3240, 2978, 1702, 1653, 1538, 1187, 1085, 870; ESI-MS $300(\mathrm{M}+\mathrm{H}) ; \mathrm{C}_{16} \mathrm{H}_{17} \mathrm{~N}_{3} \mathrm{O}_{3}$; (299.32); Calcd: C, 64.20; H, 5.72; N, 14.04; O, 16.04. Found: C, 63.89; H, 5.93; N, 14.37; O, 16.09.

5-(Ethoxycarbonyl)-4-(3-quinoline)-6-methyl-3,4-dihydropyrimidin-2(1H)-one (1q). Mp $245-247^{\circ} \mathrm{C}$; ${ }^{1} \mathrm{H}-\mathrm{NMR}$ $\left(\mathrm{DMSO}-d_{6}\right) \delta: 9.25(\mathrm{~s}, 1 \mathrm{H}, \mathrm{NH}), 7.73(\mathrm{~s}, 1 \mathrm{H}, \mathrm{NH})$, $8.32(\mathrm{~s}, 1 \mathrm{H}), 7.63-7.79(\mathrm{~m}, 4 \mathrm{H}), 7.80(\mathrm{~s}, 1 \mathrm{H}), 5.12(\mathrm{~d}, 1 \mathrm{H}$, $J=2.8 \mathrm{~Hz}), 4.11(\mathrm{q}, 2 \mathrm{H}, J=7.5 \mathrm{~Hz}), 2.28(\mathrm{~s}, 3 \mathrm{H}), 1.09(\mathrm{t}$, $3 \mathrm{H}, J=7.5 \mathrm{~Hz}$ ); ${ }^{13} \mathrm{C}-\mathrm{NMR}\left(\mathrm{DMSO}-d_{6}\right) \delta: 172.50,155.25$, $153.35,148.10,147.15,135.05,135.05,129.10,127.30$, $126.45,126.10,104.50,60.10,53.00,14.90,13.90$; IR ( $\nu_{\max }$; $\left.\mathrm{KBr}, \mathrm{cm}^{-1}\right)$ : 3408, 3365, 3280, 1698, 1640, 1513, 1227, 779; ESI-MS $312(\mathrm{M}+\mathrm{H}) ; \mathrm{C}_{17} \mathrm{H}_{17} \mathrm{~N}_{3} \mathrm{O}_{3}$ (311.34); Calcd: C, 65.58; H, 5.50; N, 13.50; O, 15.42. Found: C, 65.63; H, 5.61; $\mathrm{N}, 13.42 ; \mathrm{O}, 15.37$.

5-(Ethoxycarbonyl)-4-(2-pyrimidine)-6-methyl-3,4-dihydropyrimidin-2(1H)-one (1r). Mp $255-257^{\circ} \mathrm{C} ;{ }^{1} \mathrm{H}-\mathrm{NMR}$ $\left(\mathrm{DMSO}_{6}\right) \delta: 9.20(\mathrm{~s}, 1 \mathrm{H}, \mathrm{NH}), 7.65(\mathrm{~s}, 1 \mathrm{H}, \mathrm{NH}), 8.42$ $(\mathrm{d}, 2 \mathrm{H}, J=7.5 \mathrm{~Hz}), 7.38(\mathrm{t}, 1 \mathrm{H}, J=7.5 \mathrm{~Hz}), 5.10(\mathrm{~d}$, $1 \mathrm{H}, J=3.5 \mathrm{~Hz}), 4.02(\mathrm{q}, 2 \mathrm{H}, J=7.0 \mathrm{~Hz}), 2.23(\mathrm{~s}, 3 \mathrm{H})$, $1.11(\mathrm{t}, 3 \mathrm{H}, J=7.0 \mathrm{~Hz}) ;{ }^{13} \mathrm{C}-\mathrm{NMR}$ (DMSO- $\left.d_{6}\right) \delta: 172.60$, $168.70,157.20,155.85,153.85,119.90,104.20,60.10,56.10$, 15.15, 13.90; IR $\left(\nu_{\max } ; \mathrm{KBr}, \mathrm{cm}^{-1}\right): 3413,3385,3245,2965$, 1709, 1658, 1540, 1235, 1090, 780; ESI-MS $263(\mathrm{M}+\mathrm{H})$; $\mathrm{C}_{12} \mathrm{H}_{14} \mathrm{~N}_{4} \mathrm{O}_{3}$; (262.26); Calcd: C, 54.96; H, 5.38; N, 21.36; O, 18.30. Found: C, 54.84; H, 5.29; N, 22.04; O, 18.75.

5-(Ethoxycarbonyl)-4-(4-hydroxyl-2H(1)-benzopyran-2-one3-yl)-6-methyl-3,4-dihydropyrimi din-2(1H)-one (1t). 277$279^{\circ} \mathrm{C} ;{ }^{1} \mathrm{H}-\mathrm{NMR}$ (DMSO-d $) \delta: 11.85(\mathrm{~s}, 1 \mathrm{H}, \mathrm{OH}), 9.80(\mathrm{~s}$, $1 \mathrm{H}, \mathrm{NH}), 7.69$ (s, 1H, NH), 7.30-7.80 (m, 4H), $4.85(\mathrm{~d}, 1 \mathrm{H}$, $J=3.5 \mathrm{~Hz}), 4.23(\mathrm{q}, 2 \mathrm{H}, J=6.8 \mathrm{~Hz}), 2.35(\mathrm{~s}, 3 \mathrm{H}), 1.21(\mathrm{t}$, $3 \mathrm{H}, J=6.8 \mathrm{~Hz}) ;{ }^{13} \mathrm{C}-\mathrm{NMR}\left(\mathrm{DMSO}-d_{6}\right) \delta: 172.50,171.20$, $164.15,155.10,153.60,152.20,131.15,129.80,122.30$, $121.10,117.80,116.25,94.50,60.20,43.25,15.15,14.15$; IR $\left(\nu_{\max } ; \mathrm{KBr}, \mathrm{cm}^{-1}\right): 3389,3240,2943,1721,1705,1619$, 1562, 1235, 1123, 810; ESI-MS $345(\mathrm{M}+\mathrm{H}) ; \mathrm{C}_{17} \mathrm{H}_{16} \mathrm{~N}_{2} \mathrm{O}_{6}$; (344.32); Calcd: C, 59.30; H, 4.68; N, 8.14; O, 27.88. Found: C, 59.24; H, 4.76; N, 8.07; O, 28.01.

4,6-diphenyl-3,4-dihydropyrimidin-2(1H)-one (2a). Mp $233-236^{\circ} \mathrm{C}$; ${ }^{1} \mathrm{H}-\mathrm{NMR}$ (DMSO-d 6 ) $\delta: 9.51(\mathrm{~s}, 1 \mathrm{H}, \mathrm{NH})$, $9.21(\mathrm{~s}, 1 \mathrm{H}, \mathrm{NH}), 7.21-7.62(\mathrm{~m}, 10 \mathrm{H}, \mathrm{Ar}-\mathrm{H}), 5.20(\mathrm{~d}, 1 \mathrm{H}$, $J=4.1 \mathrm{~Hz}, \mathrm{C}=\mathrm{CH}), 5.12(\mathrm{~d}, 1 \mathrm{H}, J=4.1 \mathrm{~Hz}, \mathrm{CH}) ;{ }^{13} \mathrm{C}-\mathrm{NMR}$ $\left(\mathrm{DMSO}-d_{6}\right) \delta: 150.2,143.2,136.6,134.2,128.6,126.4,128.7$, 126.9, 97.5, 51.9; IR $\left(\nu_{\max } ; \mathrm{KBr}, \mathrm{cm}^{-1}\right): 3312,1685,1598$, 1449; ESI-MS $251(\mathrm{M}+\mathrm{H})$; $\mathrm{C}_{16} \mathrm{H}_{14} \mathrm{~N}_{2} \mathrm{O}$; (250.30); Calcd. C, 76.78; H, 5.64; N, 11.19; O, 6.39. Found. C, 76.53; H, 5.34; $\mathrm{N}, 11.02 ; \mathrm{O}, 6.13$.

4-(4-chlorophenyl)-6-phenyl-3,4-dihydropyrimidin-2(1H)one $(\mathbf{2 b})$. Mp 267-269 ${ }^{\circ}$; ${ }^{1} \mathrm{H}-\mathrm{NMR}$ (DMSO-d $\left.d_{6}\right) \delta: 9.42$ (s, 1H, NH), $9.12(\mathrm{~s}, 1 \mathrm{H}, \mathrm{NH}), 7.19-7.78(\mathrm{~m}, 9 \mathrm{H}, \mathrm{Ar}-\mathrm{H})$, $5.60(\mathrm{~d}, 1 \mathrm{H}, J=4.3 \mathrm{~Hz}, \mathrm{C}=\mathrm{CH}), 5.01(\mathrm{~d}, 1 \mathrm{H}, J=4.3 \mathrm{~Hz}$, $\mathrm{CH}) ;{ }^{13} \mathrm{C}-\mathrm{NMR}\left(\mathrm{DMSO}-d_{6}\right) \delta: 150.2,141.3,136.6,134.2$, $132.3,128.6,128.3,128.7,126.4,97.5,51.9$; IR ( $\nu_{\max }$; $\mathrm{KBr}$, $\left.\mathrm{cm}^{-1}\right): 3319,1683,1569,1463$; ESI-MS $285(\mathrm{M}+\mathrm{H})$; $\mathrm{C}_{16} \mathrm{H}_{13} \mathrm{ClN}_{2} \mathrm{O}_{3}$; (284.74); Calcd. C, 67.49; H, 4.60; Cl, 12.45, $\mathrm{N}, 9.84, \mathrm{O}, 5.62$. Found. C, 67.18; H, 4.24; Cl, 12.21; N, 9.32, $\mathrm{O}, 5.41$.

4-(4-methoxyphenyl)-6-phenyl-3,4-dihydropyrimidin-2(1H)one (2d). Mp 259-261 ${ }^{\circ} \mathrm{C} ;{ }^{1} \mathrm{H}-\mathrm{NMR}$ (DMSO- $\left.d_{6}\right) \delta: 9.23$ (s, 
1H, NH), 8.87 (s, 1H, NH), 7.18-7.56 (m, 9H, Ar-H), 5.85 $(\mathrm{d}, 1 \mathrm{H}, J=5.6 \mathrm{~Hz}, \mathrm{C}=\mathrm{CH}), 5.26(\mathrm{~d}, 1 \mathrm{H}, J=5.6 \mathrm{~Hz}, \mathrm{CH})$, $3.69\left(\mathrm{~s}, 3 \mathrm{H}, \mathrm{OCH}_{3}\right) ;{ }^{13} \mathrm{C}-\mathrm{NMR}\left(\mathrm{DMSO}-d_{6}\right) \delta: 158.6,150.2$, $136.6,135.5,134.2,127.9,114.1,128.7,128.0,126.4,97.5$, 55.8, 51.9; IR ( $\left.\nu_{\max } ; \mathrm{KBr}, \mathrm{cm}^{-1}\right): 3345,1645,1536,1422$; ESI-MS $281(\mathrm{M}+\mathrm{H}) ; \mathrm{C}_{17} \mathrm{H}_{16} \mathrm{~N}_{2} \mathrm{O}_{2}$; (280.32); Calcd. C, 72.84; H, 5.75, N, 9.99; O, 11.42. Found. C, 72.53; H, 5.42; $\mathrm{N}, 9.73 ; \mathrm{O}, 11.19$.

4,8-diphenyloctahydro-1H-pyrimido[5,4-i]quinazoline-2,10 $(3 \mathrm{H}, 11 \mathrm{H})$-dione $(\mathbf{3 a})$. Mp $327-329^{\circ} \mathrm{C} ;{ }^{1} \mathrm{H}-\mathrm{NMR}$ (DMSO$\left.d_{6}\right) \delta: 7.40-7.19(\mathrm{~m}, 10 \mathrm{H}), 7.08(\mathrm{~s}, 1 \mathrm{H}), 6.97(\mathrm{~s}, 1 \mathrm{H}), 6.62$ $(\mathrm{s}, 1 \mathrm{H}), 6.39(\mathrm{~s}, 1 \mathrm{H}), 4.50(\mathrm{~d}, 1 \mathrm{H}), 4.82(\mathrm{~d}, 1 \mathrm{H}), 2.02(\mathrm{~m}$, $2 \mathrm{H}), 1.38(\mathrm{~m}, 2 \mathrm{H}), 1.24(\mathrm{~m}, 2 \mathrm{H}), 0.82(\mathrm{t}, 2 \mathrm{H}) ;{ }^{13} \mathrm{C}-\mathrm{NMR}$ $\left(\mathrm{DMSO}-d_{6}\right) \delta: 155.9,140.5,128.1,128.6,126.0,63.7,50.2$, 49.1, 17.8; ESI-MS $377(\mathrm{M}+\mathrm{H})$; $\mathrm{C}_{22} \mathrm{H}_{24} \mathrm{~N}_{4} \mathrm{O}_{2}$; (376.45); Calcd. C, 70.19; H, 6.43; N, 14.88; O, 8.50. Found. C, 70.03; $\mathrm{H}, 6.21 ; \mathrm{N}, 14.45 ; \mathrm{O}, 8.23$.

4,8-bis(2-chlorophenyl)octahydro-1H-pyrimido[5,4-i]quinazoline-2,10(3H, 11H)-dione (3d). Mp 321-323 ${ }^{\circ} \mathrm{C} ;{ }^{1} \mathrm{H}-\mathrm{NMR}$ $\left(\mathrm{DMSO}-d_{6}\right) \delta: 7.42(\mathrm{~s}, 1 \mathrm{H}), 7.35-7.10(\mathrm{~m}, 9 \mathrm{H}), 6.75(\mathrm{~s}, 1 \mathrm{H})$, $5.32(\mathrm{~s}, 1 \mathrm{H}), 5.32(\mathrm{~s}, 1 \mathrm{H}), 3.91(\mathrm{~m}, 3 \mathrm{H}), 3.69(\mathrm{~m}, 3 \mathrm{H}), 2.30$ $(\mathrm{m}, 2 \mathrm{H}), 2.01(\mathrm{~m}, 1 \mathrm{H}), 1.84(\mathrm{~m}, 1 \mathrm{H}), 1.32(\mathrm{~m}, 1 \mathrm{H}), 1.19$ $(\mathrm{m}, 1 \mathrm{H}), 0.89(\mathrm{~m}, 1 \mathrm{H}) ;{ }^{13} \mathrm{C}-\mathrm{NMR}$ (DMSO- $\left.d_{6}\right) \delta: 155.9$, 140.5, 133.4, 129.5, 128.6, 127.4, 63.7, 48.6, 45.1, 23.6, 17.8; ESI-MS $445(\mathrm{M}+\mathrm{H}) ; \mathrm{C}_{22} \mathrm{H}_{22} \mathrm{Cl}_{2} \mathrm{~N}_{4} \mathrm{O}_{2}$ (445.34); Calcd. C, 59.33; H, 4.98; Cl, 15.92; N, 12.58; O, 7.19. Found. C, 59.12; $\mathrm{H}, 4.56 ; \mathrm{Cl}, 15.74 ; \mathrm{N}, 12.28 ; \mathrm{O}, 7.02$.

\section{Conclusion}

In conclusion, we have developed a simple, efficient, environmentally benign, and improved protocol for the synthesis of 3,4-dihydropyrimidin-2(1H)-ones/thiones over Amberlyst 15 DRY as the catalyst with excellent yields. The simplicity of the system, ease of separation/reuse of the catalyst due to its heterogeneous nature, excellent yields of the products, and ease of workup fulfill the triple bottom line philosophy of green chemistry and make the present methodology environmentally benign.

\section{Conflict of Interests}

S. R. Jetti declares that there is no conflict of interests.

\section{Acknowledgments}

One of the authors (S. R. Jetti) is grateful to Madhya Pradesh Council of Science and Technology (MPCST), Bhopal, for the award of fellowship. The authors are also thankful to Deputy Director and Head, SAIF, Central Drug Research Institute (CDRI), Lucknow, for providing spectral data and the Department of Chemistry, Vikram University, Ujjain, for extending laboratory facilities and IR data.

\section{References}

[1] J. H. Clark, Ed., Catalysis of Organic Reactions by Supported Reagents, VCH Publishers, New York, NY, USA, 1994.

[2] R. A. Sheldon and H. Van Bekkum, Catalysis through Heterogeneous Catalysis, Wiely-VCH, Weinheim, Germany, 2002.

[3] G. D. Yadav and M. S. Krishnan, "An ecofriendly catalytic route for the preparation of perfumery grade methyl anthranilate from anthranilic acid and methanol," Organic Process Research \& Development, vol. 2, no. 2, pp. 86-95, 1998.

[4] G. D. Yadav and P. K. Goel, "Selective synthesis of perfumery grade cyclohexyl esters from cyclohexene and carboxylic acids over ion exchange resins: an example of 100\% atom economy," Green Chemistry, vol. 2, no. 2, pp. 71-78, 2000.

[5] S. M. Mahajani and M. M. Sharma, "Reaction of glyoxal with aliphatic alcohols using cationic exchange resins as catalysts," Organic Process Research and Development, vol. 1, no. 2, pp. 97-105, 1997.

[6] A. K. Kolah, S. M. Mahajani, and M. M. Sharma, "Acetalization of formaldehyde with methanol in batch and continuous reactive distillation columns," Industrial and Engineering Chemistry Research, vol. 35, no. 10, pp. 3707-3720, 1996.

[7] G. D. Yadav and A. V. Joshi, "A green route for the acylation of resorcinol with acetic acid," Clean Technologies and Environmental Policy, vol. 4, no. 3, pp. 157-164, 2002.

[8] S. B. Patil, R. P. Bhat, and S. D. Samant, "Cation-exchange resins: efficient heterogeneous catalysts for facile synthesis of dibenzoxanthene from $\beta$-naphthol and aldehydes," Synthetic Communications, vol. 36, no. 15, pp. 2163-2168, 2006.

[9] C. O. Kappe, "Dipolar cycloaddition reactions of dihydropyrimidine-fused mesomeric betaines: an approach toward conformationally restricted dihydropyrimidine derivatives," Journal of Organic Chemistry, vol. 62, no. 10, pp. 3109-3118, 1997.

[10] F. Bossert and W. Vater, "1,4-Dihydropyridines-a basis for developing new drugs," Medicinal Research Reviews, vol. 9, no. 3, pp. 291-324, 1989.

[11] K. S. Atwal, G. C. Rovnyak, J. Schwartz et al., "Dihydropyrimidine calcium channel blockers: 2-heterosubstituted 4aryl-1,4-dihydro-6-methyl-5-pyrimidinecarboxylic acid esters as potent mimics of dihydropyridines," Journal of Medicinal Chemistry, vol. 33, no. 5, pp. 1510-1515, 1990.

[12] K. Folkers and T. B. Johnson, "Researches on pyrimidines. CXXXIII. Some reactions and derivatives of 2-keto-4-phenyl5-carbethoxy-6-methyl-1,2,3,4-tetrahydropyrimidine,"

Journal of the American Chemical Society, vol. 55, no. 7, pp. 2886-2893, 1933.

[13] E. H. Hu, D. R. Sidler, and U. H. Dolling, "Unprecedented catalytic three component one-pot condensation reaction: an efficient synthesis of 5-alkoxycarbonyl-4-aryl-3,4dihydropyrimidin- 2(1H)-ones," Journal of Organic Chemistry, vol. 63, no. 10, pp. 3454-3457, 1998.

[14] J. Lu, Y. Bai, Z. Wang, B. Yang, and H. Ma, "One-pot synthesis of 3,4-dihydropyrimidin-2(1H)-ones using lanthanum chloride as a catalyst," Tetrahedron Letters, vol. 41, no. 47, pp. 9075-9078, 2000.

[15] D. S. Bose, L. Fatima, and H. B. Mereyala, "Green chemistry approaches to the synthesis of 5-alkoxycarbonyl-4aryl-3,4-dihydropyrimidin-2(1H)-ones by a three-component coupling of one-pot condensation reaction: comparison of ethanol, water, and solvent-free conditions," Journal of Organic Chemistry, vol. 68, no. 2, pp. 587-590, 2003.

[16] B. C. Ranu, A. Hajra, and U. Jana, "Indium(III) chloridecatalyzed one-pot synthesis of dihydropyrimidinones by 
a three-component coupling of 1,3-dicarbonyl compounds, aldehydes, and urea: an improved procedure for the Biginelli reaction," Journal of Organic Chemistry, vol. 65, no. 19, pp. 6270-6272, 2000.

[17] E. Rafiee and H. Jafari, "A practical and green approach towards synthesis of dihydropyrimidinones: using heteropoly acids as efficient catalysts," Bioorganic and Medicinal Chemistry Letters, vol. 16, no. 9, pp. 2463-2466, 2006.

[18] K. Ramalinga, P. Vijayalakshmi, and T. N. B. Kaimal, "Bismuth(III)-catalyzed synthesis of dihydropyrimidinones: improved protocol conditions for the Biginelli reaction," Synlett, no. 6, pp. 863-865, 2001.

[19] A. S. Paraskar, G. K. Dewkar, and A. Sudalai, "Cu(OTf) $)_{2}$ : a reusable catalyst for high-yield synthesis of 3,4-dihydropyrimidin-2(1H)-ones," Tetrahedron Letters, vol. 44, no. 16, pp. 3305-3308, 2003.

[20] J.-P. Wan and Y.-J. Pan, "Chemo-/regioselective synthesis of 6-unsubstituted dihydropyrimidinones, 1,3-thiazines and chromones via novel variants of Biginelli reaction," Chemical Communications, no. 19, pp. 2768-2770, 2009.

[21] J. S. Yadav, B. V. Subba Reddy, R. Srinivas, C. Venugopal, and $\mathrm{T}$. Ramalingam, " $\mathrm{LiClO}_{4}$-catalyzed one-pot synthesis of dihydropyrimidinones: an improved protocol for Biginelli reaction," Synthesis, no. 9, pp. 1341-1345, 2001.

[22] G. Maiti, P. Kundu, and C. Guin, "One-pot synthesis of dihydropyrimidinones catalysed by lithium bromide: an improved procedure for the Biginelli reaction," Tetrahedron Letters, vol. 44, no. 13, pp. 2757-2758, 2003.

[23] N. Y. Fu, Y. F. Yuan, Z. Cao, S. W. Wang, J. T. Wang, and C. Peppe, "Indium(III) bromide-catalyzed preparation of dihydropyrimidinones: improved protocol conditions for the Biginelli reaction," Tetrahedron, vol. 58, no. 24, pp. 4801-4807, 2002.

[24] M. M. Abelman, S. C. Smith, and D. R. James, "Cyclic ketones and substituted $\alpha$-keto acids as alternative substrates for novel Biginelli-like scaffold syntheses," Tetrahedron Letters, vol. 44, no. 24, pp. 4559-4562, 2003.

[25] J. Lu and H. Ma, "Iron(III)-catalyzed synthesis of dihydropyrimidinones: improved conditions for the Biginelli reaction," Synlett, no. 1, pp. 63-64, 2000.

[26] G. Sabitha, G. S. K. Reddy, C. S. Reddy, and J. S. Yadav, "Onepot synthesis of dihydropyrimidinones using iodotrimethylsilane. Facile and new improved protocol for the Biginelli reaction at room temperature," Synlett, no. 6, pp. 858-860, 2003.

[27] A. V. Narsaiah, A. K. Basak, and K. Nagaiah, "Cadmium chloride: an efficient catalyst for one-pot synthesis of 3,4dihydropyrimidin-2(1H)-ones," Synthesis, no. 8, pp. 12531256, 2004.

[28] V. N. Pathak, R. Gupta, and B. Varshney, "An efficient, inexpensive "Green Chemistry" route to multicomponent Biginelli condensation catalyzed by $\mathrm{CuCl}_{2} \cdot 2 \mathrm{H}_{2} \mathrm{O}-\mathrm{HCl}$," Indian Journal of Chemistry B, vol. 47, no. 3, pp. 434-438, 2008.

[29] A. A. Ashraf and Abdel-Fattah, "Expedient synthesis of Biginelli-type dihydropyrimidinones using $\alpha$-(benzotriazolyl) alkyl urea derivatives," Synthesis, no. 15, pp. 2358-2362, 2003.

[30] S. H. Chandak, P. N. Lad, and P. P. Upare, "Recyclable amberlyst-70 as a catalyst for Biginelli reaction: an efficient one-pot green protocol for the synthesis of 3,4-dihydropyrimidin-2(1H)-ones," Catalysis Letters, vol. 131, no. 3-4, pp. 469-473, 2009.
[31] K.-Y. Lee and K.-Y. Ko, "Envirocat EPZ-10: a recyclable solid acid catalyst for the synthesis of Biginelli-type 3,4dihydropyrimidin-2(1H)-ones," Bulletin of the Korean Chemical Society, vol. 25, no. 12, pp. 1929-1931, 2004.

[32] A. Chaskar, F. Jaffer, B. Langi, S. Yewale, and A. Bodkhe, "Indion 190 resin: a green and recyclable catalyst for facile and efficient one-pot synthesis of 3, 4-dihydropyrimidin-2(1H)one," Journal of the Korean Chemical Society, vol. 53, no. 2, pp. 224-228, 2009.

[33] C. O. Kappe, "Recent advances in the Biginelli dihydropyrimidine synthesis. New tricks from an old dog," Accounts of Chemical Research, vol. 33, no. 12, pp. 879-888, 2000.

[34] Z.-T. Wang, L.-W. Xu, C.-G. Xia, and H.-Q. Wang, "Novel Biginelli-like three-component cyclocondensation reaction: efficient synthesis of 5-unsubstituted 3,4-dihydropyrimidin2(1H)-ones," Tetrahedron Letters, vol. 45, no. 42, pp. 79517953, 2004.

[35] A. Saini, S. Kumar, and J. S. Sandhu, "Aluminium(III) halides mediated synthesis of 5-unsustituted 3,4-dihydropyrimidin2(1H)-ones via three component Biginelli-like reaction," Indian Journal of Chemistry B, vol. 46, no. 10, pp. 1690-1694, 2007. 


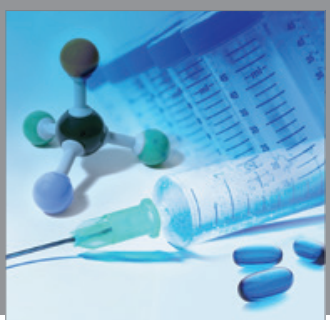

International Journal of

Medicinal Chemistry

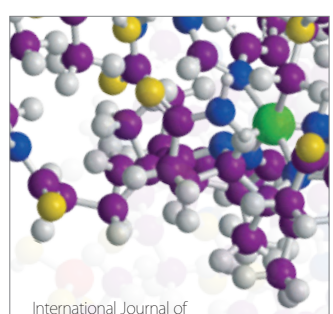

Carbohydrate Chemistry

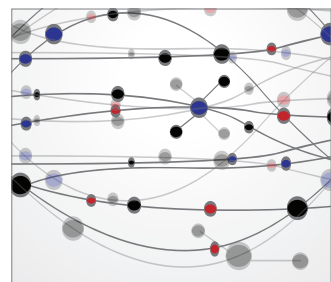

The Scientific World Journal
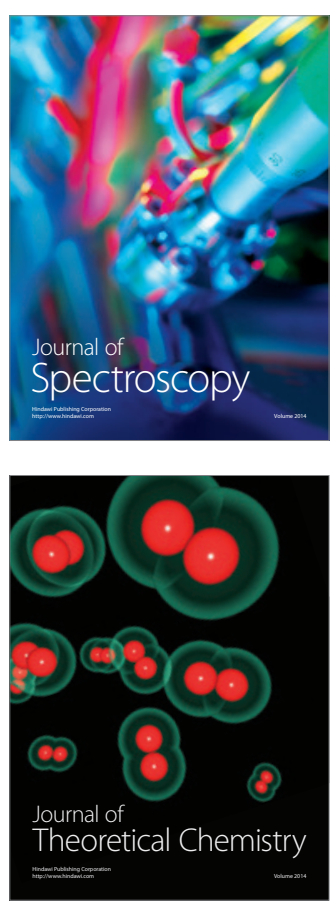
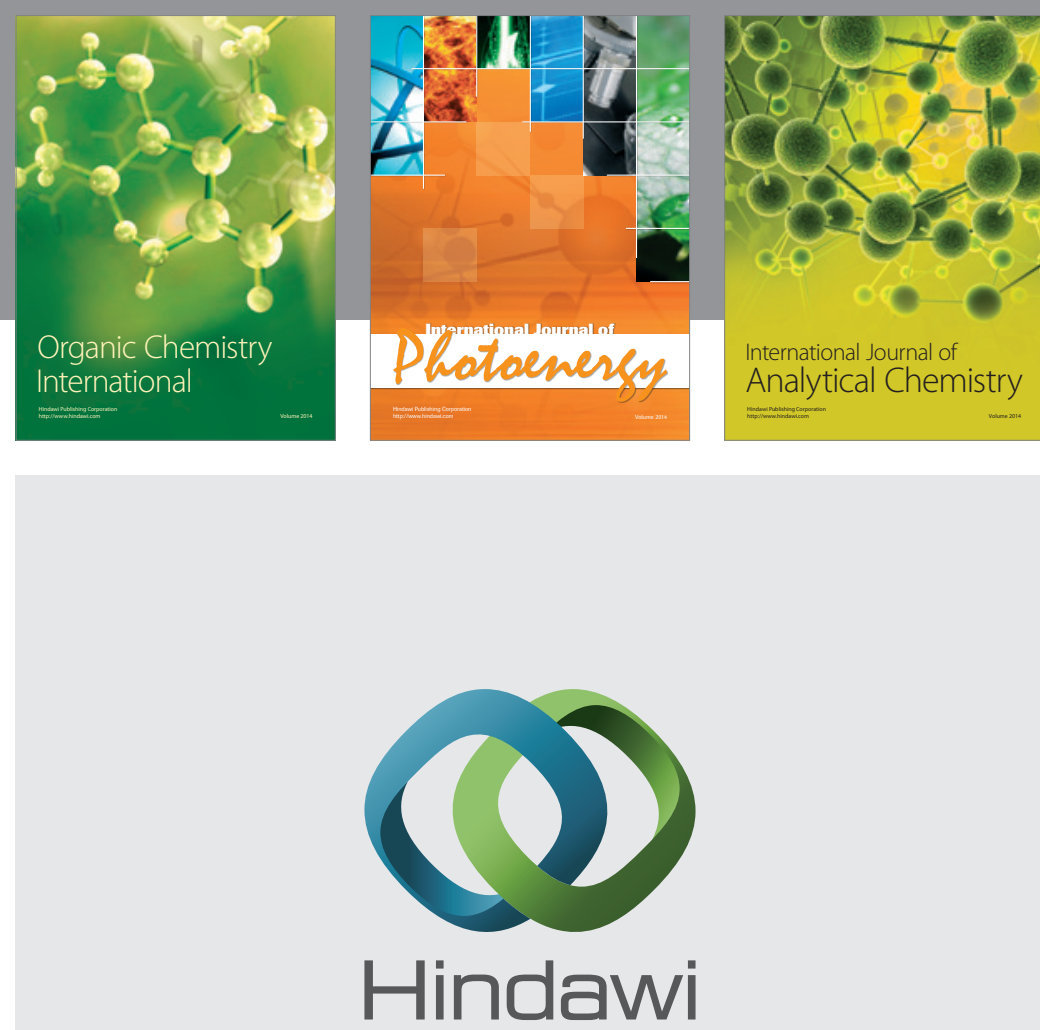

Submit your manuscripts at

http://www.hindawi.com
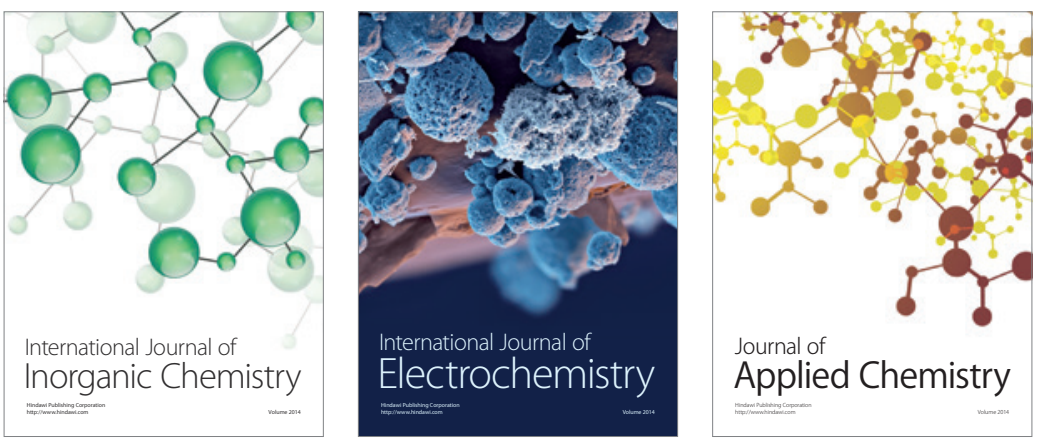

Journal of

Applied Chemistry
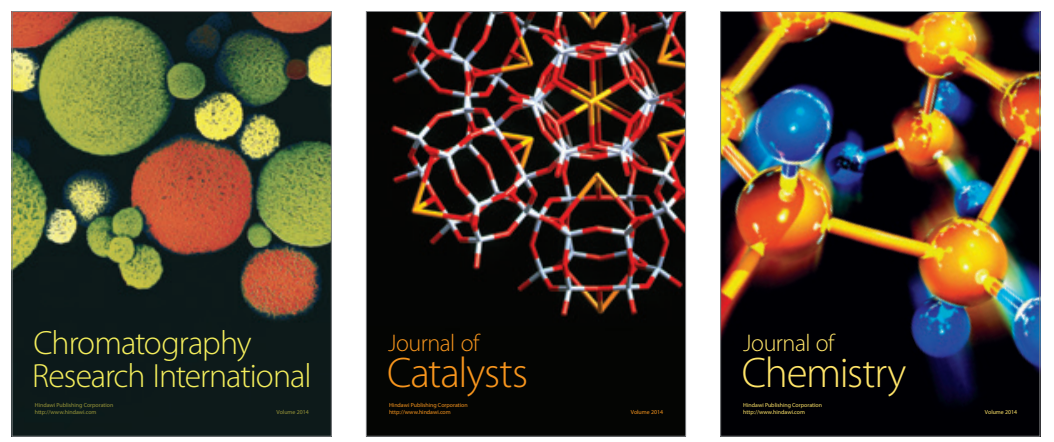
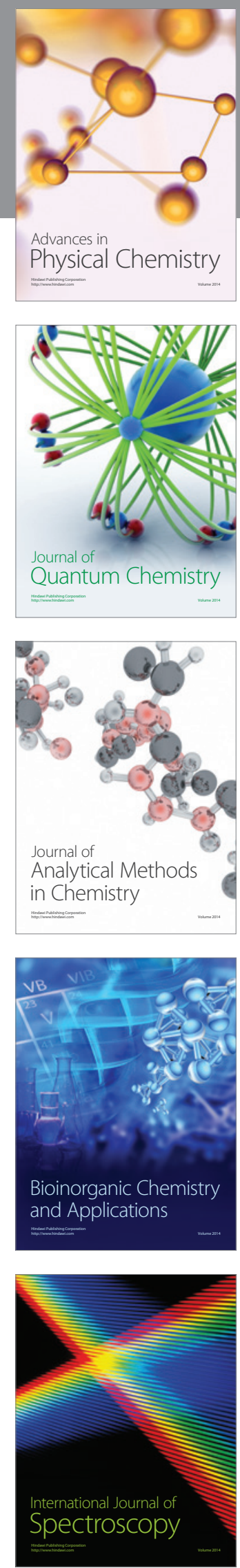